\title{
Facing coronavirus disease 2019: What do we know so far? (Review)
}

\author{
QIE GUO, WEN XU, PAN-FENG WANG, HONG-YAN JI, XIAO-LEI ZHANG, KAI WANG and JING LI \\ Department of Pharmacy, The Affiliated Hospital of Qingdao University, Qingdao, Shandong 266003, P.R. China
}

Received June 6, 2020; Accepted March 22, 2021

DOI: $10.3892 / \mathrm{etm} .2021 .10090$

\begin{abstract}
Although the World Health Organization declared the outbreak of coronavirus disease 2019 (COVID-19), which originated in China, as a public health emergency of international concern as early as January 30, 2020, the current COVID-19 epidemic is spreading rapidly. As of April 19, 2020, total of 2,392,165 confirmed cases had been reported in 211 countries and regions, with 614,421 (25.68\%) cured cases and 164,391 (6.87\%) deaths. Scientists and clinicians have made great efforts to learn much about COVID-19 so that it can be controlled as soon as possible. Herein, this review will discuss the epidemiology, pathology, clinical features, diagnosis and treatment of COVID-19 based on the current evidence.
\end{abstract}

\section{Contents}

1. Introduction

2. Epidemiology

3. Pathology

4. Clinical characteristics

5. Effective treatment

6. Conclusions and prospects

\section{Introduction}

At the beginning of December 2019, a cluster of mysterious pneumonia cases was reported in Hubei Province of the People's Republic of China, and a novel coronavirus was identified as the common cause of this unexplained pneumonia (1). The virus and the associated disease were named severe acute respiratory syndrome coronavirus 2 (SARS-CoV-2)

Correspondence to: Dr Jing Li, Department of Pharmacy, The Affiliated Hospital of Qingdao University, 16 Jiangsu Road, Qingdao, Shandong 266003, P.R. China

E-mail: 1ijing7112@126.com

Key words: coronavirus, severe acute respiratory syndrome coronavirus 2, coronavirus disease 2019 and coronavirus disease 2019 (COVID-19), respectively, by the World Health Organization (2). With the spread of this epidemic, COVID-19 has been identified in other parts of China and around the world. It is urgent to combat this deadly contagious disease with increasing incidence.

Coronaviruses are enveloped, positive-sense, singlestranded RNA viruses and include $\alpha$-coronavirus $(\alpha-\mathrm{CoV})$, $\beta$-coronavirus $(\beta-\mathrm{CoV}), \delta$-coronavirus $(\delta-\mathrm{CoV})$ and g-coronavirus $(\gamma-\mathrm{CoV})(3)$. Six coronaviruses were previously identified as human-susceptible viruses, among which HCoV-OC43, HCoV-229E, HCoV-NL63, and HCoV-HKU1 cause mild respiratory illness (4). Two other notorious coronaviruses, severe acute respiratory syndrome coronavirus (SARS-CoV) and Middle East respiratory syndrome coronavirus (MERS-CoV), have stronger transmission capacity and high mortality rates $(5,6)$. SARS-CoV-2 is the seventh member of the coronavirus family that infects human beings after SARS-CoV and MERS-CoV were described. Similar to SARS-CoV and MERS-CoV, SARS-CoV-2 is also a $\beta-\mathrm{CoV}$; however, the genome sequence is significantly different from those of SARS-CoV and MERS-CoV (7). Specific recognition mediated by the spike protein and angiotensin-converting enzyme 2 has been revealed to be crucial for SARS-CoV-2 attachment and membrane fusion in host cells (8).

Several reports have described the epidemiology, pathology, clinical manifestations, diagnosis and treatment of COVID-19, and this review provides comprehensive insights on COVID-19 based on the emerging evidence.

\section{Epidemiology}

Currently, the human-to-human transmission mode of SARS-CoV-2 has been verified, including in both COVID-19-diagnosed and asymptomatically infected patients. The major route of SARS-CoV-2 transmission is through respiratory droplets and close contact (9). Moreover, SARS-CoV-2 can also be propagated by exposure to high-concentration aerosols for a long time in a relatively closed environment. Additionally, SARS-CoV-2 has been isolated from feces and urine; thus, particular attention should be given to the spread of aerosols or contact with environmental pollution containing feces and urine (10). Based on the current epidemiological survey, the incubation period of SARS-CoV-2 ranges from 1 to 14 days, with most cases becoming symptomatic within 3 to 7 days, indicating that individuals with 
close contact must undergo 14 days of medical observation or isolation (11). However, some asymptomatic carriers have been reported to have an incubation period of 30 days, which is concerning for the population that is generally susceptible to SARS-CoV-2 (12). This characteristic comprises a persistent challenge for the prevention and control of COVID-19.

\section{Pathology}

The pathological manifestations of patients with SARS-CoV-2 infection are limited due to the scarcity of biopsies or autopsies. The changes in the lungs are the most noticeable characteristic. Firstly, serous, fibrin exudate and hyaline membranes are found in the alveoli, with the exudate cells mainly including monocytes and macrophages (13). Secondly, type II alveolar epithelial cells filled with inclusion bodies show significant proliferation, and some detach (14). Thirdly, hyperemia, edema, infiltration of monocytes and lymphocytes, and the formation of hyaline thrombi in the alveolar septa occur. Hemorrhagic infarction resulting from focal hemorrhage and necrosis of lung tissue have also been observed (15). Moreover, the spleen shows obvious shrinking, and the histological features include focal involvement of a decreased number of $\mathrm{CD}^{+}{ }^{+} \mathrm{T}$ and $\mathrm{CD} 8^{+} \mathrm{T}$ cells (16). Degeneration and necrosis can also be seen in cardiomyocytes that are infiltrated by a small number of monocytes, lymphocytes and/or neutrophils (17). Additionally, the liver and gallbladder exhibit a dark red color with an increased volume. Moreover, hepatocyte degeneration and focal necrosis with neutrophil infiltration can be found in the portal area (18). The renal tubular epithelium is denatured and exfoliated with microthrombi and focal fibrosis (19). In summary, the pathological features of COVID-19 greatly resemble those of SARS-CoV and MERS-CoV infection $(20,21)$.

\section{Clinical characteristics}

The spectrum of clinical manifestations of COVID-19 includes a self-reported fever, dry cough and fatigue (22). A small number of patients have been reported to have nasal obstruction, runny nose, sore throat, myalgia and diarrhea (23). Severe cases often involve dyspnea and/or hypoxemia one week after COVID-19 onset, which rapidly progress to acute respiratory distress syndrome (ARDS), septic shock, metabolic acidosis, coagulation dysfunction and multiple organ failure without obvious fever (24). However, the main symptoms in children and newborns with SARS-CoV-2 infection are not typical and include vomiting, diarrhea and gastrointestinal discomfort or only mental confusion and shortness of breath (25).

Patients with COVID-19 can be divided into mild, common, severe and critical types according to the severity of symptoms. Mild or no pneumonia is found on chest computed tomography (CT) images of mild patients. Pneumonia is also commonly presented by patients with a self-reported fever and some respiratory symptoms. Severe patients have overt symptoms, including dyspnea, respiratory rate $\geq 30 / \mathrm{min}$, blood oxygen saturation $\leq 93 \%$, an arterial oxygen partial pressure to inspired oxygen fraction $\left(\mathrm{FiO}_{2}\right)$ ratio of $<300$, and/or pulmonary infiltration $>50 \%$ within $24-48$ h $(26-28)$. A child with shortness of breath ( $<2$ months old, respiratory rate $\geq 60 \mathrm{~min}$; 2-12 months old, respiratory rate $\geq 50 / \mathrm{min}$; $1-5$ years old, respiratory rate $\geq 40 / \mathrm{min} ;>5$ years old, respiratory rate $\geq 30 / \mathrm{min}$ ), oxygen saturation $\leq 93 \%$, assisted respiration (moaning, alar flutter, three concave signs), cyanosis, intermittent apnea, drowsiness, convulsion, refusal to eat or feed, and dehydration signs should be considered as having the severe type (29). Critical patients have worsened medical conditions, such as respiratory failure, septic shock and multiple organ failure, or may even require immediate respiratory support with mechanical ventilation and intensive care unit monitoring and treatment (30).

Clinical laboratory indicators in COVID-19 patients are diverse and can be regarded as discriminatory tools to define patient types.

Serological examination. In almost all patients, the total number of leukocytes in the peripheral blood is normal or decreased, and the lymphocyte count is decreased (31). Half of patients have abnormal liver function, which is manifested as elevation of alanine aminotransferase or aspartate aminotransferase levels. Most patients have an abnormal myocardial zymogram, showing increases in creatine kinase and lactate dehydrogenase (32). The C-reactive protein (CRP) level and erythrocyte sedimentation rate are increased in most patients who show normal serum levels of procalcitonin, D-dimer, inflammatory factors, myoglobin and even troponin, which are often increased in severe and critical patients (33). It should be noted that hyperinflammatory syndrome is characterized by increased interleukin (IL)-2, IL-7, IL-6, granulocyte colony-stimulating factor, interferon (IFN)- $\gamma$-inducible protein 10 , IL-8, IL-9, IL-10, basic fibroblast growth factor, monocyte chemoattractant protein 1 , macrophage inflammatory protein $1-\alpha$, and tumor necrosis factor (TNF)- $\alpha$ (34). Physicians should be alert for the 'inflammatory storm' and end-organ damage caused by the increase in inflammatory factors.

Etiological examination. Real time-polymerase chain reaction (RT-PCR) and/or next-generation sequencing methods can be used to detect the RdRP, N, and E genes of the SARS-CoV-2 genome in nasopharyngeal swabs, blood and feces samples (35). The SARS-CoV-2 genome is more complicated to detect in lower respiratory tract samples (sputum or airway extracts), and indicated samples should be sent for examination as soon as possible after collection (36).

Chest CT imaging. Chest CT imaging results show multiple small-spot shadows and interstitial changes, especially in the extrapulmonary zone, which develop into multiple ground glass opacities and infiltrative shadows in both lungs (37). Lung consolidation and pleural effusion are seldom observed in severe patients.

Suspected COVID-19 cases are classified based on the epidemiological history and clinical manifestations. Patients with a history of travel or residence in a community in which confirmed cases have been reported or individuals with contact with infected persons (positive for nucleic acid detection) within 14 days prior to the onset of the 'COVID-19 manifestations' should be suspected of being infected with 
Table I. Details of drugs indicated for treatment of coronavirus disease 2019.

\begin{tabular}{|c|c|c|c|}
\hline Drugs & Status & Recommended dosage & Refs. \\
\hline Lopinavir/ritonavir tables & Approved & 2 tablets, bid & $(46)$ \\
\hline Oseltamivir & Approved & $\begin{array}{l}75 \mathrm{mg} \text {, bid for prevention } \\
75 \mathrm{mg} \text {, qd for treatment }\end{array}$ & $(47)$ \\
\hline Ribavirin & Approved & $500 \mathrm{mg}$, bid or tid for ivgtt & $(48)$ \\
\hline Ganciclovir & Investigational & Controversial & $(49)$ \\
\hline Remdesivir & Experimental & Controversial & $(51)$ \\
\hline$\alpha$-Interferon & Recommended in China & 5 million $\mathrm{U}$, bid for nebulization & $(52)$ \\
\hline Chloroquine & Controversial & $\begin{array}{l}\text { For those weighing >50 kg: } 500 \mathrm{mg} \text {, bid for } 7 \text { days; } \\
\text { for those weighing <50 kg: } 500 \mathrm{mg} \text {, bid for the first } \\
\text { and second days, followed by } 500 \mathrm{mg} \text {, qd from the } \\
\text { third to the seventh days }\end{array}$ & $(53)$ \\
\hline Arbidol & Recommended in China & $200 \mathrm{mg}$, tid for no more than 10 days & $(54)$ \\
\hline Lianhua Qingwen capsule & Recommended in China & $1.4 \mathrm{mg}, \mathrm{tid}$ & $(34)$ \\
\hline Shuanghuanglian oral liquid & Recommended in China & $20 \mathrm{ml}$, tid & $(34)$ \\
\hline Methylprednisolone & Controversial & $1-2 \mathrm{mg} / \mathrm{kg}, \mathrm{qd}$ & $(55)$ \\
\hline Topiramab & Approved & $4-8 \mathrm{mg} / \mathrm{kg}, \mathrm{qd}$ & (34) \\
\hline
\end{tabular}

bid, twice a day; qd, one time a day; tid, three times a day; ivgtt, intravenous drip.

SARS-CoV-2 (38). COVID-19 manifestations include fever and/or respiratory symptoms, chest CT imaging features, and normal or decreased numbers of white blood cells and lymphocytes (39).

COVID-19 cases are further identified in suspected infected patients based on pathogenic or serological evidence. Particularly, confirmed cases include suspected infected patients in whom nucleotide fragments for the SARS-CoV-2 genome are successfully detected by RT-PCR or in whom the genes of the causative virus are highly homologous to those of the known coronavirus as determined by genomic typing and sequence analysis (40). Furthermore, confirmed patients are positive for SARS-CoV-2-specific IgM and $\mathrm{IgG}$ antibodies, and the accumulated levels are four times higher than the levels in the acute phase (34).

RT-PCR is regarded as a convincing method for the identification of pathogenic viruses in respiratory secretions (41). However, some patients in Wuhan were diagnosed as confirmed cases according to typical symptoms, exposure history and chest CT manifestations without nucleic acid testing due to the shortage of RT-PCR testing kits (42). In the early stage of COVID-19, the positive rate of RT-PCR was $\sim 60 \%$ for throat swabs (43). In addition, a study was carried out to compare the diagnostic value of chest CT imaging and RT-PCR in patients suspected with SARS-CoV-2. The results showed that the sensitivities of chest CT based on positive and negative RT-PCR results were 97 and 75\%, respectively (44). Therefore, chest CT imaging and RT-PCR are both powerful tools for diagnosing COVID-19 and are complementary to each other.

\section{Effective treatment}

Patients with suspected and confirmed COVID-19 should be treated in single rooms of a designated hospital with effective isolation and protective conditions as much as possible. The treatment of patients with COVID-19 is as follows.

General supportive care. It is necessary to instruct the patient to lie in bed and ensure a sufficient temperature. The oxygen saturation, fluid and electrolyte balance, the complete blood count, CRP, and liver, coagulation and kidney functions should also be closely monitored (45). The administration of high-flow oxygen and even an admixture of hydrogen and oxygen $\left(\mathrm{H}_{2} / \mathrm{O}_{2}: 66.65 / 33.39 \%\right)$ should be performed in a timely manner (34).

Drug treatment. Currently, no specific drug has been approved for therapy, but some indicated medications can be used on a trial basis.

The development of antiviral drugs has received continuous attention since the outbreak of COVID-19. Antiviral-drug candidates including lopinavir/ritonavir, oseltamivir, ribavirin and ganciclovir have been used to optimally decrease viral shedding and subsequent transmission (46-49). However, the results of an urgent randomized clinical trial performed by Cao et al (50) were disappointing, indicating that lopinavir/ ritonavir are not effective in patients with COVID-19 (50). Remdesivir was also reported to be effective, but only in the treatment of a patient with COVID-19 in the United States (51). Thus, rapidly initiated, high-quality, randomized clinical trials need to be performed to verify the efficacy of these antiviral drugs for COVID-19. In addition, IFN- $\alpha$, chloroquine phosphate and Arbidol, which have been shown to be effective in decreasing the SARS-CoV load in cell culture, were also empirically used in Wuhan (52-54). The use of three or more antiviral drugs at the same time is not recommended, and indicated drugs should be stopped if intolerable side effects occur. Blind or inappropriate use of broad-spectrum antibiotics 
should be avoided unless secondary bacterial infection occurs. The treatment practice of COVID-19 in China indicated that intervention with Traditional Chinese medicine (TCM) is an important management strategy to improve the prognosis and prevent the deterioration of patients with COVID-19. TCM prescriptions such as qingfei paidu decoction, gancaoganjiang decoction, sheganmahuang decoction, qingfei touxie fuzheng recipe, and Chinese traditional patent medicines including Lianhua Qingwen capsule and Shuanghuanglian oral liquid were all commonly used (34). Corticosteroids were used for short-term treatment (3-5 days), as appropriate, but high-dose corticosteroids can increase the immunosuppressive effect, thus delaying the SARS-CoV-2 clearance (55). Detailed information for the drugs indicated for COVID-19 treatment is supplied in Table I.

Treatment of severe and critical cases. The treatment of patients with severe and critical cases is rather difficult to manage. For such patients, the principle of treatment is to actively prevent and treat complications and secondary infection, and to rapidly improve the organ function via respiratory and circulatory support.

Patients with severe and critical cases must be given oxygen using nasal catheters or face masks. When respiratory distress and/or hypoxemia cannot be relieved after standard oxygen treatment, high-flow oxygen should be administered, and noninvasive ventilation may be considered (56). If the condition does not improve or even worsens in a short period of time (1-2 h), intubation and invasive mechanical ventilation should be carried out immediately. It is noteworthy that low tidal volume $(6-8 \mathrm{ml} / \mathrm{kg})$ and airway platform pressure $\left(\leq 30 \mathrm{cmH}_{2} \mathrm{O}\right.$ ) are needed to decrease ventilator-associated lung injury (57). Patients with severe ARDS will require salvage treatment as soon as possible. In particular, more than $12 \mathrm{~h}$ of prone position ventilation should be performed every day (58). Moreover, extracorporeal membrane oxygenation can be implemented when the $\mathrm{FiO}_{2}$ is $>90 \%$ and the oxygenation index is $<80 \mathrm{mmHg}$ for 3-4 $\mathrm{h}$ (59).

Vasoactive drugs are also encouraged to improve microcirculation in patients with severe and critical cases, and changes in blood pressure, heart rate and urine volume, as well as elevations of lactate and alkali levels in the arterial blood must be closely monitored. These patients should also be assessed for septic shock, gastrointestinal hemorrhage and heart failure when a sudden increase in heart rate of $>20 \%$ or a decrease in blood pressure of $>20 \%$ of the baseline value occurs, accompanied by poor skin perfusion and decreased urine volume (60).

The cytokine storm seems to induce damage to the lungs or multiple organs and can affect patients with severe conditions (61). During the COVID-19 outbreak in China, blood purification treatments were used to clear inflammatory factors and block the cytokine storm, thus protecting host organs from damage (62). Furthermore, blocking IL-6 with tocilizumab may be an effective measure, and blocking IL-1 and TNF-a may also benefit patients (63). Mesenchymal stromal/stem cells have been shown to exert their anti-inflammatory effects in patients with severe COVID-19 infection (64). However, more solid evidence needs to be accumulated.

Various clinical sites in China have also declared that continuous renal replacement therapy and plasma from convalescent populations are suitable for patients with severe and critical illness (65). However, evidence has yet to be accumulated.

Overall, symptomatic treatment is vital for patients with COVID-19, and many outstanding issues need to be clarified in the process of pursuing effective treatment for COVID-19.

\section{Conclusions and prospects}

The outbreak of COVID-19 is ravaging many countries that bear a large burden of morbidity and mortality, which has been reported as $\sim 3.41 \%$, compared with $10 \%$ for SARS and $35 \%$ for MERS in China $(66,67)$. Nevertheless, it is too early to evaluate the total mortality because the current COVID-19 outbreak in the United States and European countries is moving rapidly.

Early diagnosis by rapid and reliable technologies, early isolation in a community or designated hospital, and early treatment with individualized programs have been helpful for managing COVID-19. Staying at home, limiting social contacts, wearing masks in public and using necessary disinfectants are the best strategies to protect healthy individuals from SARS-CoV-2 infection. However, it is possible that humans will coexist with SARS-CoV-2 for a long time until specific drugs and vaccines become available.

\section{Acknowledgements}

Not applicable.

\section{Funding}

This work was supported by Natural Science Foundation of Shandong Province, China (grant no. ZR2020QH362).

\section{Availability of data and materials}

Not applicable.

\section{Authors' contributions}

HYJ and XLZ contributed to the conception and design of the present study. WX, PFW and KW consulted relevant references and performed the literature data collection. QG wrote the first draft of the manuscript. JL revised the manuscript. Data authentication is not applicable. All authors have read and approved the final version of the manuscript.

\section{Ethics approval and consent to participate}

Not applicable.

\section{Patient consent for publication}

Not applicable.

\section{Competing interests}

The authors declare that they have no competing interests. 


\section{References}

1. Wuhan Municipal Health Commission. Report of clustering pneumonia of unknown etiology in Wuhan City. 2019. http://wjw. wuhan.gov.cn/front/web/showDetail/2019123108989. Accessed December 31, 2019

2. WHO. Novel coronavirus (2019-nCoV) situation report 11. Jan 31, 2020. https://www.who.int/docs/default-source/coronaviruse/ situation-reports/20200131-sitrep-11-ncov.pdf?sfvrsn=de7c0f7_4 Accessed February 18, 2020.

3. Zumla A, Chan JF, Azhar EI, Hui DS and Yuen KY: Coronaviruses-drug discovery and therapeutic options. Nat Rev Drug Discov 15: 327-347, 2016.

4. Yin Y and Wunderink RG: MERS, SARS and other coronaviruses as causes of pneumonia. Respirology 23: 130-137, 2018.

5. Cheng VC, Lau SK, Woo PC and Yuen KY: Severe acute respiratory syndrome coronavirus as an agent of emerging and reemerging infection. Clin Microbiol Rev 20: 660-694, 2007

6. Chan JF, Lau SK and Woo PC: The emerging novel Middle East respiratory syndrome coronavirus: The 'knowns' and 'unknowns'. J Formos Med Assoc 112: 372-381, 2013.

7. Paraskevis D, Kostaki EG, Magiorkinis G, Panayiotakopoulos G, Sourvinos G and Tsiodras S: Full-genome evolutionary analysis of the novel corona virus (2019-nCoV) rejects the hypothesis of emergence as a result of a recent recombination event. Infect Genet Evol 79: 104212, 2020.

8. Zhou P, Yang XL, Wang XG, Hu B, Zhang L, Zhang W, Si HR, Zhu Y, Li B, Huang CL, et al: A pneumonia outbreak associated with a new coronavirus of probable bat origin. Nature 579: $270-273,2020$

9. Li Q, Guan X, Wu P, Wang X, Zhou L, Tong Y, Ren R, Leung KSM, Lau EHY, Wong JY, et al: Early transmission dynamics in Wuhan, China, of novel coronavirus-infected pneumonia. N Engl J Med 382: 1199-1207, 2020.

10. Xia J, Tong J, Liu M, Shen Y and Guo D: Evaluation of coronavirus in tears and conjunctival secretions of patients with SARS-CoV-2 infection. J Med Virol 92: 589-594, 2020.

11. Chan JF, Yuan S, Kok KH, To KK, Chu H, Yang J, Xing F, Liu J, Yip CC, Poon RW, et al: A familial cluster of pneumonia associated with the 2019 novel coronavirus indicating person-to-person transmission: A study of a family cluster. Lancet 395 : 514-523, 2020.

12. Bai Y, Yao L, Wei T, Tian F, Jin DY, Chen L and Wang M: Presumed asymptomatic carrier transmission of COVID-19. JAMA 323: 1406-1407, 2020.

13. Xu Z, Shi L, Wang Y, Zhang J, Huang L, Zhang C, Liu S, Zhao P, Liu H, Zhu L, et al: Pathological findings of COVID-19 associated with acute respiratory distress syndrome. Lancet Respir Med 8: 420-422, 2020.

14. Tian S, Hu W, Niu L, Liu H, Xu H and Xiao SY: Pulmonary pathology of early-phase 2019 novel coronavirus (COVID-19) pneumonia in two patients with lung cancer. J Thorac Oncol 15: 700-704, 2020.

15. Wang LS, Wang YR, Ye DW and Liu QQ: A review of the 2019 novel coronavirus (COVID-19) based on current evidence. Int J Antimicrob Agents 55: 105948, 2020.

16. Velavan TP and Meyer CG: The COVID-19 epidemic. Trop Med Int Health 25: 278-280, 2020

17. Inciardi RM, Lupi L, Zaccone G, Italia L, Raffo M, Tomasoni D, Cani DS, Cerini M, Farina D, Gavazzi E, et al: Cardiac involvement in a patient with coronavirus disease 2019 (COVID-19). JAMA Cardiol 5: 819-824, 2020.

18. Zhang C, Shi L and Wang FS: Liver injury in COVID-19. Management and challenges. Lancet Gastroenterol Hepatol 5: $428-430,2020$

19. Ficarra V, Novara G, Abrate A, Bartoletti R, Crestani A, De Nunzio C, Giannarini G, Gregori A, Liguori G, Mirone V, et al: Urology practice during the COVID-19 pandemic. Minerva Urol Nefrol 72: 369-375, 2020

20. Ding Y, Wang H, Shen H, Li Z, Geng J, Han H, Cai J, Li X, Kang W, Weng D, et al: The clinical pathology of severe acute respiratory syndrome (SARS): A report from China. J Pathol 200: 282-289, 2003

21. Ng DL, Al Hosani F, Keating MK, Gerber SI, Jones TL, Metcalfe MG, Tong S, Tao Y, Alami NN, Haynes LM, et al: Clinicopathologic, immunohistochemical, and ultrastructura findings of a fatal case of Middle East respiratory syndrome coronavirus infection in the United Arab Emirates, April 2014 Am J Pathol 186: 652-658, 2016.
22. Wu F, Zhao S, Yu B, Chen YM, Wang W, Song ZG, Hu Y, Tao ZW, Tian JH, Pei YY, et al: A new coronavirus associated with human respiratory disease in China. Nature 579: 265-269, 2020.

23. Wang D, Hu B, Hu C, Zhu F, Liu X, Zhang J, Wang B, Xiang H, Cheng Z, Xiong Y, et al: Clinical characteristics of 138 hospitalized patients with 2019 novel coronavirus-infected pneumonia in Wuhan, China. JAMA 323: 1061-1069, 2020.

24. Huang C, Wang Y, Li X, Ren L, Zhao J, Hu Y, Zhang L, Fan G, $\mathrm{Xu} \mathrm{J}, \mathrm{Gu}$ X, et al: Clinical features of patients infected with 2019 novel coronavirus in Wuhan, China. Lancet 395: 497-506, 2020.

25. Ogimi C, Englund JA, Bradford MC, Qin X, Boeckh M and Waghmare A: Characteristics and outcomes of coronavirus infection in children: The role of viral factors and in immunocompromised state. J Pediatric Infect Dis Soc 8: 21-28, 2019.

26. Wu Z and McGoogan JM: Characteristics of and important lessons from the coronavirus disease 2019 (COVID-19) outbreak in China: Summary of a report of 72314 cases from the Chinese center for disease control and prevention. JAMA 323: 1239-1242, 2020.

27. Jiang F, Deng L, Zhang L, Cai Y, Cheung CW and Xia Z: Review of the clinical characteristics of coronavirus disease 2019 (COVID-19). J Gen Intern Med 35: 1545-1549, 2020.

28. Mo P, Xing Y, Xiao Y, Deng L, Zhao Q, Wang H, Xiong Y, Cheng Z, Gao S, Liang K, et al: Clinical characteristics of refractory COVID-19 pneumonia in Wuhan, China. Clin Infect Dis: Mar 16, 2020 (Epub ahead of print). doi: 10.1093/cid/ciaa270.

29. Liu W, Zhang Q, Chen J, Xiang R, Song H, Shu S, Chen L, Liang L, Zhou J, You L et al: Detection of Covid-19 in children in early January 2020 in Wuhan, China. N Engl J Med 382: $1370-1371,2020$

30. National Health Commission of the People's Republic of China: Notice of the general office of the national health and health commission on issuing a new coronavirus pneumonia prevention and control plan (fourth edition). http://www.nhc.gov. cn/xcs/zhengcwj/202002/573340613ab243b3a7f61df260551dd4. shtml. Accessed February 17, 2020.

31. Chen N, Zhou M, Dong X, Qu J, Gong F, Han Y, Qiu Y, Wang J, Liu Y, Wei Y, et al: Epidemiological and clinical characteristics of 99 cases of 2019 novel coronavirus pneumonia in Wuhan, China: A descriptive study. Lancet 395: 507-513, 2020.

32. Rodriguez-Morales AJ, Cardona-Ospina JA, Gutiérrez-OcampoE, Villamizar-Peña R, Holguin-Rivera Y, Escalera-Antezana JP, Alvarado-Arnez LE, Bonilla-Aldana DK, Franco-Paredes C, Henao-Martinez AF, et al: Clinical, laboratory and imaging features of COVID-19: A systematic review and meta-analysis. Travel Med Infect Dis 34: 101623, 2020.

33. Gao Y, Li T, Han M, Li X, Wu D, Xu Y, Zhu Y, Liu Y, Wang X and Wang L: Diagnostic utility of clinical laboratory data determinations for patients with the severe COVID-19. J Med Virol 92: 791-796, 2020.

34. National Health Commission of the People's Republic of China: Notice of the general office of the national health and health commission on issuing the guidelines for the diagnosis and treatment of pneumonia infected by new coronavirus (trial seventh edition). Mar 4, 2020.

35. Corman VM, Landt O, Kaiser M, Molenkamp R, Meijer A, Chu DK, Bleicker T, Brünink S, Schneider J, Schmidt ML, et al: Detection of 2019 novel coronavirus (2019-nCoV) by real-time RT-PCR. Euro Surveill 25: 2000045, 2020.

36. Yang Y, Yang M, Shen C, Wang F, Yuan J, Li J, Zhang M, Wang Z, Xing L, Wei J, et al: Evaluating the accuracy of different espiratory specimens in the laboratory diagnosis and monitoring the viral shedding of 2019-nCoV infections. medRxiv: 2020.02.11.20021493, 2020. doi: https://doi.org/10.1101/2020.02.11.20021493.

37. Pan Y, Guan H, Zhou S, Wang Y, Li Q, Zhu T, Hu Q and Xia L: Initial CT findings and temporal changes in patients with the novel coronavirus pneumonia (2019-nCoV): A study of 63 patients in Wuhan, China. Eur Radiol 30: 3306-3309, 2020

38. Riou J and Althaus CL: Pattern of early human-to-human transmission of Wuhan 2019 novel coronavirus $(2019-\mathrm{nCoV})$, December 2019 to January 2020. Euro Surveill 25: 2000058, 2020.

39. Hageman JR: The coronavirus disease 2019 (COVID-19). Pediatr Ann 49: e99-e100, 2020.

40. Wang W, Tang J and Wei F: Updated understanding of the outbreak of 2019 novel coronavirus (2019-nCoV) in Wuhan, China. J Med Virol 92: 441-447, 2020 
41. Chan JF, Lau SK, To KK, Cheng VC, Woo PC and Yuen KY: Middle East respiratory syndrome coronavirus: Another zoonotic betacoronavirus causing SARS-like disease. Clin Microbiol Rev 28: 465-522, 2015.

42. Shi H, Han X, Jiang N, Cao Y, Alwalid O, Gu J, Fan Y and Zheng C: Radiological findings from 81 patients with COVID-19 pneumonia in Wuhan, China: A descriptive study. Lancet Infect Dis 20: 425-434, 2020.

43. Pan F, Ye T, Sun P, Gui S, Liang B, Li L, Zheng D, Wang J, Hesketh R, Yang L and Zheng C: Time course of lung changes on chest CT during recovery from 2019 novel coronavirus (COVID-19) pneumonia. Radiology 295: 200370, 2020

44. Ai T, Yang Z, Hou H, Zhan C, Chen C, Lv W, Tao Q, Sun Z and Xia L: Correlation of chest CT and RT-PCR testing in coronavirus disease 2019 (COVID-19) in China: A report of 1014 cases. Radiology 296: E32-E40, 2020.

45. Binnicker MJ: Emergence of a novel coronavirus disease (COVID-19) and the importance of diagnostic testing: Why partnership between clinical laboratories, public health agencies, and industry is essential to control the outbreak. Clin Chem 66 664-666, 2020.

46. Guo YR, Cao QD, Hong ZS, Tan YY, Chen SD, Jin HJ, Tan KS, Wang DY and Yan Y: The origin, transmission and clinical therapies on coronavirus disease 2019 (COVID-19) outbreak-an update on the status. Mil Med Res 7: 1, 2020.

47. Mahase E: China coronavirus: What do we know so far? BMJ 368: $\mathrm{m} 308,2020$.

48. Mitjà $\mathrm{O}$ and Clotet $\mathrm{B}$ : Use of antiviral drugs to reduce COVID-19 transmission. Lancet Glob Health 8: e639-e640, 2020.

49. National Health Commission of the People's Republic of China. Notice of the general office of the national health and health commission on issuing the guidelines for the diagnosis and treatment of pneumonia infected by new coronavirus (sixth version) Feb 19, 2020

50. Cao B, Wang Y, Wen D, Liu W, Wang J, Fan G, Ruan L, Song B, Cai Y, Wei M, et al: A trial of lopinavir-ritonavir in adults hospitalized with severe Covid-19. N Engl J Med 382: 1787-1799, 2020

51. Holshue ML, DeBolt C, Lindquist S, Lofy KH, Wiesman J, Bruce H, Spitters C, Ericson K, Wilkerson S, Tural A, et al: First case of 2019 novel coronavirus in the United States. N Engl J Med 382: 929-936, 2020.

52. Luo H, Tang QL, Shang YX, Liang SB, Yang M, Robinson N and Liu JP: Can Chinese medicine be used for prevention of corona virus disease 2019 (COVID-19)? A review of historical classics, research evidence and current prevention programs. Chin J Intesgr Med 26: 243-250, 2020.

53. Touret $\mathrm{F}$ and de Lamballerie $\mathrm{X}$ : Of chloroquine and COVID-19. Antiviral Res 177: 104762,2020.

54. Khamitov RA, Loginova SIa, Shchukina VN, Borisevich SV, Maksimov VA and Shuster AM: Antiviral activity of arbidol and its derivatives against the pathogen of severe acute respiratory syndrome in the cell cultures. Vopr Virusol 53: 9-13, 2008 (In Russian).
55. Arabi YM, Mandourah Y, Al-Hameed F, Sindi AA, Almekhlafi GA, Hussein MA, Jose J, Pinto R, Al-Omari A, Kharaba A, et al: Corticosteroid therapy for critically ill patients with Middle East respiratory syndrome. Am J Respir Crit Care Med 197: 757-767, 2018

56. Hui DS, Chow BK, Lo T, Tsang OTY, Ko FW, Ng SS, Gin T and Chan MTV: Exhaled air dispersion during high-flow nasal cannula therapy versus CPAP via different masks. Eur Respir J 53: 1802339, 2019.

57. Yang X, Yu Y, Xu J, Shu H, Xia J, Liu H, Wu Y, Zhang L, Yu Z, Fang M, et al: Clinical course and outcomes of critically ill patients with SARS-CoV-2 pneumonia in Wuhan, China: A single-centered, retrospective, observational study. Lancet Respir Med 8: 475-481, 2020.

58. Cheung JC, Ho LT, Cheng JV, Cham EYK and Lam KN: Staff safety during emergency airway management for COVID-19 in Hong Kong. Lancet Respir Med 8: e19, 2020,

59. Namendys-Silva SA: Respiratory support for patients with COVID-19 infection. Lancet Respir Med 8: e18, 2020.

60. Zheng YY, Ma YT, Zhang JY and Xie X: COVID-19 and the cardiovascular system. Nat Rev Cardiol 17: 259-260, 2020.

61. Mehta P, McAuley DF, Brown M, Sanchez E, Tattersall RS and Manson JJ; HLH Across Speciality Collaboration, UK: COVID-19: Consider cytokine storm syndromes and immunosuppression. Lancet 395: 1033-1034, 2020.

62. Shi Y, Wang Y, Shao C, Huang J, Gan J, Huang X, Bucci E, Piacentini M, Ippolito G and Melino G: COVID-19 infection: The perspectives on immune responses. Cell Death Differ 27: 1451-1454, 2020

63. Khiali S, Khani E and Entezari-Maleki T: A comprehensive review of tocilizumab in COVID-19 acute respiratory distress syndrome. J Clin Pharmacol 60: 1131-1146, 2020.

64. Stebbing J, Phelan A, Griffin I, Tucker C, Oechsle O, Smith D and Richardson P: COVID-19: Combining antiviral and anti-inflammatory treatments. Lancet Infect Dis 20: 400-402, 2020.

65. Guan WJ, Ni ZY, Hu Y, Liang WH, Ou CQ, He JX, Liu L, Shan H, Lei CL, Hui DSC, et al: Clinical characteristics of coronavirus disease 2019 in China. N Engl J Med 382: 1708-1720, 2020.

66. Del Rio C and Malani PN: COVID-19-new insights on a rapidly changing epidemic. JAMA 323: 1339-1340, 2020.

67. He F, Deng Y and Li W: Coronavirus disease 2019: What we know? J Med Virol 92: 719-725, 2020

This work is licensed under a Creative Commons Attribution-NonCommercial-NoDerivatives 4.0 International (CC BY-NC-ND 4.0) License. 